J.Lake Sci.(湖泊科学), 2016, 28( 1): 86-93

DOI 10. 18307/2016. 0110

(C) 2016 by Journal of Lake Sciences

\title{
非稳沉采煤沉陷区沉积物一水体界面的氮、磷分布及迁移转化特征
}

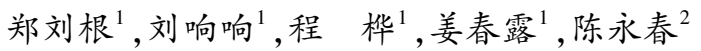 \\ ( 1 : 安徽大学资源与环境工程学院矿山环境修复与湿地生态安全协同创新中心, 合肥 230601) \\ (2:煤矿生态环境保护国家工程实验室,淮南 232001)
}

\begin{abstract}
摘 要: 以淮南后湖非稳沉采煤沉陷区沉积物一水体界面为研究对象, 分析该湖未开发区 ( A 区) 、水产养殖区 ( B 区) 和水 生蔬菜种植区 ( C 区 ) 3 个功能区上覆水一间隙水-沉积物体系中氮、磷分布及其迁移特征. 结果表明, 氮、磷在不同水体界 面的分布差异较大. 其中上覆水中氮、磷浓度表现为 $\mathrm{A}$ 区 $>\mathrm{B}$ 区 $>\mathrm{C}$ 区; 间隙水中氮、磷分布差异不显著, 然而各功能区间隙 水的氮、磷浓度明显高于上覆水, 氮、磷主要由间隙水向上覆水中移动; 沉积物中氮、磷含量以 $\mathrm{C}$ 区最高. 后湖采煤沉陷区 水体表现出氮污染、磷限制的现象.
\end{abstract}

关键词: 采煤沉陷水体; 上覆水;间隙水;沉积物;氮; 磷; 后湖

\section{Distribution and migration characteristics of nitrogen and phosphorus in sediment-water interface from unstable coal mining subsidence area}

\author{
ZHENG Liugen ${ }^{1}$, LIU Xiangxiang ${ }^{1}$, CHENG Hua ${ }^{1}$, JIANG Chunlu ${ }^{1} \&$ CHEN Yongchun ${ }^{2}$ \\ (1: Collaborative Innovation Center for Mines Environmental Remediation and Wetland Ecological Security, School of \\ Resource and Environment Engineering, Anhui University, Hefei 230601, P.R. China) \\ (2: National Engineering Laboratory of Coal Mine Ecological Environment Protection, Huainan 232001, P.R.China)
}

Abstract: Three water bodies of different functionalities, i.e., undeveloped (A), aquaculture (B), and aquatic vegetable planting $(\mathrm{C})$, in Lake Houhu unstable coal mining subsidence area, were studied to address the distribution and migration of nitrogen and phosphorus in a column system of overlying water column, sediment pore water and sediments. The results showed that the contents of nitrogen and phosphorus were quite different in different sediment-water interface. The concentrations of nitrogen and phosphorus in overlying water column were in the order of $\mathrm{A}>\mathrm{B}>\mathrm{C}$. Although no significant difference in concentrations of nitrogen and phosphorus in pore waters of these three water bodies were observed, they were distinctly higher than those in overlying water columns. This suggested an upward migration of nitrogen and phosphorus from pore waters to overlying water columns. The highest concentrations of nitrogen and phosphorus were examined in the sediments of aquatic vegetable planting water body. Overall, the study found that water bodies were polluted by nitrogen but had limited availability of phosphorus.

Keywords: Coalmine subsidence water; overlying water column; pore water; sediment; nitrogen; phosphorus; Lake Houhu

煤炭作为我国的主要能源, 2013 年约占能源消费体系的 $65.7 \%$.煤炭在开采利用中会出现一系列生态和 环境问题, 如土地破坏、水体污染、地表植被破坏、重金属以及大气污染等 ${ }^{[1]}$, 其中, 采煤导致的地表沉陷是 最重要的生态环境问题之一. 研究资料显示, 全国煤炭开采所形成的沉陷区总量已达 $400 \times 10^{4} \mathrm{hm}^{2}$, 平均每年 新形成沉陷土地约 $3.3 \times 10^{4} \sim 4.7 \times 10^{4} \mathrm{hm}^{2[2]}$. 煤炭开采在形成地表洼地的同时, 在高潜水位、水资源丰富地区 很容易在洼地积水,根据其形态、面积以及人类改造目的不同,这些采煤沉陷积水区往往形成水塘、湖泊、湿 地、甚至平原水库等不同功能类水体, 其中具有良好水资源储存条件的两淮煤炭生产基地目前沉陷面积已

* 国家科技支撑计划项目 (2012BAC10B02)、国家自然科学基金项目 (41373108)、煤矿生态环境保护国家工程实验 室科技攻关项目 (HKKY-JT-JS2012) 、安徽省自然科学基金项目 (1208085ME66) 和安徽省教育厅重点基金项目 (KJ2012A022) 联合资助.2014-12-18 收稿;2015-05-09 收修改稿. 郑刘根 (1972 ), 男, 博士, 副教授; E-mail: lgzheng@ ustc.edu.cn. 
达 $300 \mathrm{~km}^{2}$, 预计 10 年后面积将扩大 1.6 倍, 届时将达到 $500 \mathrm{~km}^{2}$, 同时积水区面积将占 $30 \% 50 \%$, 由此引起 的沉陷区水资源利用和富营养化问题备受研究者关注 ${ }^{[3]}$.

采煤沉陷水域实质上是土壤覆水演变区域水体的过程, 水体中的营养盐浓度初期受覆水土壤岩石矿物 化学成分的作用明显 ${ }^{[4]}$, 伴随着当地经济社会的发展, 沉陷水体氮、磷浓度很容易受人类活动影响 ${ }^{[5]}$.与湖 泊、河流等天然水体相比,沉陷区水域除了具有雨水汇人、季节性变化、水质成分受湖泊面积和底质影响等 相似特点外, 采煤沉陷区水域特征与煤炭开采活动往往有紧密联系, 通常水体年龄与煤炭开采时间一致, 面 积大小不一, 数量众多, 临近水域间存在兼并联合等, 与此同时沉陷区水域有的已经大小稳定, 有些因煤炭 的持续开采还在继续扩大处于非稳沉状态, 随着今后的开发和更多沉陷土地被水体淹没而释放出更多的 氮、磷,进而增加该水体的氮、磷负荷, 采煤沉陷水域环境十分复杂 ${ }^{[6]}$.但是, 采煤沉陷区的存在具有相当的普 遍性, 在我国 14 个大型煤炭生产基地有不同程度的分布. 因此对采煤沉陷水体中的氮、磷进行研究具有重要 的现实意义.

以往大多数学者对水体中氮、磷循环过程和机理的研究主要集中在海洋、河流、天然湖泊以及湿地等传 统水体 ${ }^{[7-10]}$, 对于采煤活动形成的沉陷水体研究较少.近年来也有不少研究者开始关注沉陷区这种人为扰动

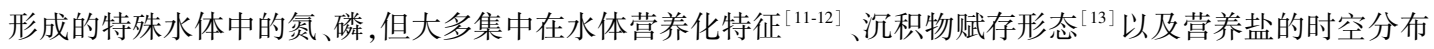
规律 ${ }^{[14-15]}$ 等方面, 对沉陷区氮、磷的迁移转化研究也仅限在实验室模拟方面 ${ }^{[16-17]}$, 具有一定的局限性, 缺乏 对氮、磷在沉积物一水体界面的系统报道.本研究选择我国典型的高潜水位、多煤层煤炭生产基地淮南矿区作 为研究对象, 对该地非稳沉类型为典型代表的后湖采煤沉陷区上覆水一间隙水一沉积物体系中氮、磷特征进 行综合分析, 比较不同功能区中氮、磷的分布和迁移差异, 旨在揭示沉陷水体的氮、磷污染迁移机理, 为高潜 水位采煤沉陷区水体综合治理和开发利用提供理论依据.

\section{1 材料与方法}

\section{1 研究区概况}

研究区域后湖采煤沉陷区位于安徽省淮南市潘集区泥河镇西部, 地处淮河北岸冲积平原, 地势平坦, 区 内水系发达, 属于典型的高潜水位地区.该地区由于地涉潘一矿和潘二矿 2 个采煤区, 多年的煤炭开采导致 了区内分布了大大小小的沉陷区, 加上地处温带季风气候, 年降雨量较为丰富, 在雨水、地下水和地表径流 的影响下沉陷区常年积水形成不少沉陷水域.

后湖地区沉陷前是一个以农业为主, 主产小麦的农耕区.2008 年开始对后湖周边约 $1 \times 10^{4} \mathrm{hm}^{2}$ 的沉陷区 进行综合治理, 已建设成一个集生态、观光、休闲、旅游于一体的生态园. 目前已完成两期共 $357 \mathrm{hm}^{2}$ 的沉陷地 的整理与利用, 园区内规划有水产养殖区、农业试验区、花卉种植区、蔬菜种植区等 10 个功能区, 各功能区 以车道、步道相互连接. 目前, 根据区内积水区功能用途将研究水域划分为 3 类, 分别为未开发区 ( A 区) 、水 产养殖区 (B 区) 和水生蔬菜区 (C 区) (图 1).

1) 未开发区:位于后湖生态园西部,水域面积最大,最大水深约 $5 \mathrm{~m}$, 一般水体深度约 $2 \mathrm{~m}$, 主要由一大 一小 2 块水区组成, 由于相近加上中间土层不高, 2 块水区水体已有连通, 处于兼并阶段. 同时该区受采煤活 动影响, 处于非沉稳状态, 有进一步下沉扩大的趋势. 该区尚未开发, 水体营养盐浓度主要受农业面源影响.

2) 水产养殖区:位于生态园中部位置, 该区是在原有较浅的采煤沉陷区挖深垫浅形成鱼塘, 深度约 $1.5 \mathrm{~m}$, 由于开挖现象水塘边缘较直、整体呈矩形, 该鱼塘有投饵活动, 属于饲料养殖.

3) 水生蔬菜区: 位于生态园东北部, 该区以莲藕种植为主, 水深约 $1 \mathrm{~m}$, 水区中间道路是以木桥搭建, 伴 有凉亭, 便于休闲观赏.

\section{2 样品采集和前处理}

于 2013 年 11 月对后湖生态园内 A 区、B 区、C 区 3 个不同的功能性水区进行样品采集,并用 GPS 定位 记录, 样点分布图如图 1 所示. 根据研究区分布, 共设置 13 个采样点, 其中 A 区 6 个( 编号 1 6); B 区 4 个 ( 编号 7 10); C 区 3 个 ( 编号 11 13). 分别在取样点处采集对应的上覆水和沉积物样品. 上覆水利用有机玻 璃采水器采集表层水水深约 $0.5 \mathrm{~m}$ 处水样, 并装入聚乙烯瓶中. 取样时现场测试表层水的温度、溶解氧、Eh 和 $\mathrm{pH}$ 值. 利用蚌式采泥器收集表面 $0 \sim 5 \mathrm{~cm}$ 沉积物样品于聚乙烯塑料袋中, 带回实验室储存于冰箱中. 将沉积 


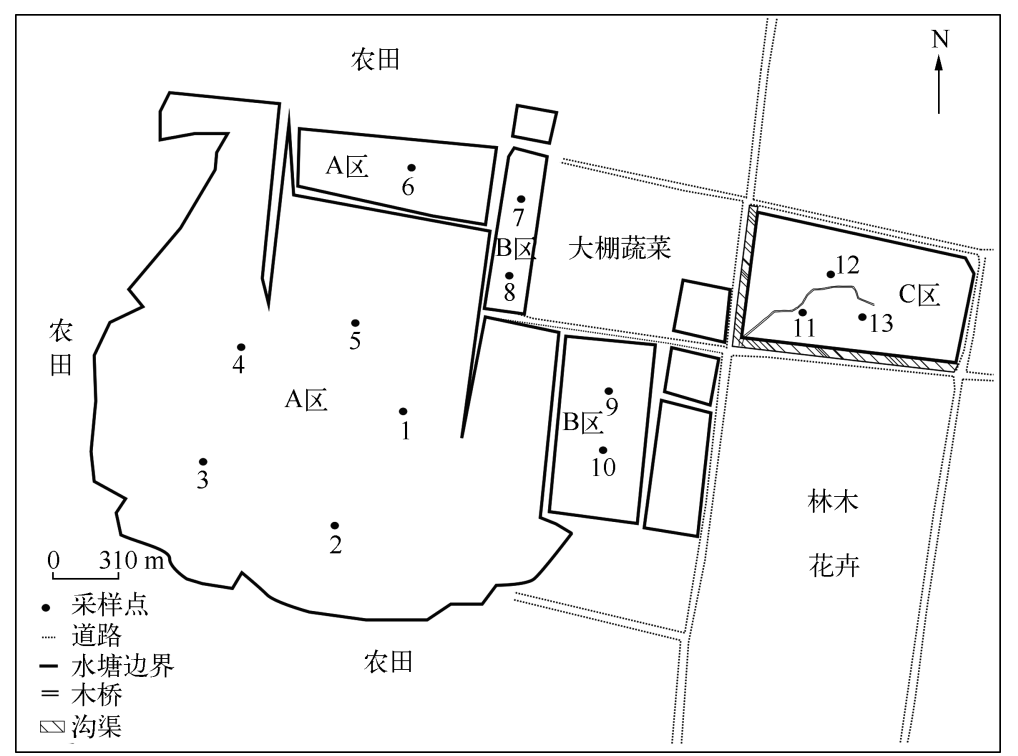

图 1 后湖采样点分布

Fig.1 Distribution of the sampling sites in Lake Houhu

物以 4300 转 $/ \mathrm{min}$ 进行泥水分离, 取上层水即间隙水, 立即用 $0.45 \mu \mathrm{m}$ 醋酸纤维滤膜进行过滤, 并储存在 $5^{\circ} \mathrm{C}$ 冰箱内备用.沉积物经冷冻干燥后, 研磨、过 100 目篮备用.

\section{3 样品分析方法}

上覆水的 $\mathrm{pH}$ 值用 $\mathrm{pH}$ 仪 (WTW $\mathrm{pH} 3110$ )、溶解氧 ( DO, mg/L) 和温度 $\left(\mathrm{T},{ }^{\circ} \mathrm{C}\right.$ ) 用溶解氧仪 (WTW oxi $315 \mathrm{i})$ 现场测定, 氧化还原电位 $\left(\mathrm{Eh}_{\mathrm{w}}, \mathrm{mV}\right)$ 用氧化还原电位仪 (ORP 计-SX712) 现场测试. 其余水质指标参照 《水和废水监测分析方法》测定, 其中 $\mathrm{COD}_{\mathrm{Cr}}(\mathrm{mg} / \mathrm{L})$ 用重铬酸钾法测定; 总氮 $\left(\mathrm{TN}_{\mathrm{w}}, \mathrm{mg} / \mathrm{L}\right)$ 浓度用碱性过硫酸 钾-紫外分光光度法测定; 总磷 $\left(\mathrm{TP}_{\mathrm{w}}, \mathrm{mg} / \mathrm{L}\right)$ 浓度用酸性过硫酸钾-钼蓝比色法测定; 叶绿素 $\mathrm{a}\left(\mathrm{Chl} . \mathrm{a}, \mathrm{mg} / \mathrm{m}^{3}\right)$ 浓度用分光光度法测定; 铵态氮 $\left(\mathrm{NH}_{4}^{+}-\mathrm{N}_{\mathrm{w}}, \mathrm{mg} / \mathrm{L}\right)$ 浓度用纳氏试剂分光光度法测定; 硝态氮 $\left(\mathrm{NO}_{3}^{-}-\mathrm{N}_{\mathrm{w}}, \mathrm{mg} / \mathrm{L}\right)$ 浓度用紫外分光光度法测定; 由于可溶性总氮 $\left(\mathrm{DIN}_{\mathrm{w}}, \mathrm{mg} / \mathrm{L}\right)$ 主要由铵态氮、硝态氮和亚硝态氮组成, 而亚硝 态氮极不稳定且浓度一般极低, 不做计算, 因此本文中 $\mathrm{DIN}_{\mathrm{w}}=\mathrm{NH}_{4}^{+}-\mathrm{N}_{\mathrm{w}}+\mathrm{NO}_{3}^{-}-\mathrm{N}_{\mathrm{w}}$; 可溶性磷酸盐 $\left(\mathrm{TDP}_{\mathrm{w}}, \mathrm{mg} / \mathrm{L}\right)$ 浓度用钿蓝比色法测定. 间隙水的总氮 $\left(\mathrm{TN}_{\mathrm{i}}\right)$ 和总磷 $\left(\mathrm{TP}_{\mathrm{i}}\right)$ 浓度分别用碱性过硫酸钾一紫外分光光度法和酸 性过硫酸钾-钼蓝比色法测定.

沉积物的总氮 $\left(\mathrm{TN}_{\mathrm{s}}, \mathrm{g} / \mathrm{kg}\right)$ 含量和碳氮比 $(\mathrm{C} / \mathrm{N})$ 利用元素分析仪测定统计; 沉积物铵态氮 $\left(\mathrm{NH}_{4}^{+}-\mathrm{N}_{\mathrm{s}}\right.$, $\mathrm{g} / \mathrm{kg})$ 和硝态氮 $\left(\mathrm{NO}_{3}^{-}-\mathrm{N}_{\mathrm{s}}, \mathrm{g} / \mathrm{kg}\right)$ 用 $1 \mathrm{~mol} / \mathrm{L} \mathrm{KCl}$ 溶液振动提取, 分别采用纳氏试剂和紫外分光光度法测定其 含量 ${ }^{[18]}$; 总磷 $\left(\mathrm{TP}_{\mathrm{s}}, \mathrm{g} / \mathrm{kg}\right)$ 含量用 $\mathrm{NaOH}$ 熔融-锄绨抗比色法测定; 速效磷 $(\mathrm{A}-\mathrm{P})$ 含量采用碳酸氢钠浸提-锄 锑抗比色法测定; 有机质含量采用烧失法 (LOI,\%) 测定.

\section{4 数据分析}

采用 SPSS 18.0 软件进行数据的统计分析, 采用 One-way ANOVA $(P<0.05)$ 进行各个功能区间均值的比 较检验,利用 Pearson 相关系数表示相关性.采用 Corel DRAW X5 和 Origin 8.5 制图.

\section{2 结果与分析}

\section{1 上覆水中的氮、磷}

后湖 $\mathrm{A}$ 区水体的 $\mathrm{TN}_{\mathrm{w}} 、 \mathrm{NH}_{4}^{+}-\mathrm{N}_{\mathrm{w}} 、 \mathrm{NO}_{3}^{-}-\mathrm{N}_{w}$ 和 $\mathrm{TP}_{\mathrm{w}}$ 平均浓度分别为 $6.60 、 0.70 、 0.24$ 和 $0.02 \mathrm{mg} / \mathrm{L} ; \mathrm{B}$ 区水体分 别为 $5.82 、 0.34 、 0.20$ 和 $0.02 \mathrm{mg} / \mathrm{L}$; C 区水体的 $\mathrm{TN}_{\mathrm{w}} 、 \mathrm{NH}_{4}^{+}-\mathrm{N}_{\mathrm{w}} 、 \mathrm{NO}_{3}^{-}-\mathrm{N}_{\mathrm{w}}$ 浓度分别为 $5.80 、 0.30 、 0.16 \mathrm{mg} / \mathrm{L}, \mathrm{TP}_{\mathrm{w}}$ 未检出. 其中水体中的 $\mathrm{TN}_{\mathrm{w}}$ 均属于劣 $\mathrm{V}$ 类, $\mathrm{A} 、 \mathrm{~B}$ 和 $\mathrm{C}$ 区 $\mathrm{TN}_{\mathrm{w}}$ 分别超出《地表水环境质量标准》( $\mathrm{GB} 3838-$ 
$2002)$ 中规定的 $\mathrm{V}$ 类水 $(2.0 \mathrm{mg} / \mathrm{L})$ 的 $230 \% 、 191 \%$ 和 $190 \%$, 后湖沉陷区水体总氮污染较为严重; A、B、C 区水 体中主要 $\mathrm{DIN}_{w}$ 浓度占 $\mathrm{TN}_{w}$ 浓度的比例分别为 $14.2 \% 、 9.3 \%$ 和 $7.9 \%$, 表明有机氮是后湖水体氮素的主要赋存 方式. 测试结果发现水体中 $\mathrm{TP}_{\mathrm{w}}$ 指标较好, 均优于 II 类标准. 不同功能区水体中的 $\mathrm{TDP}_{\mathrm{w}}$ 浓度均低于检测限, 表 明后湖沉陷区上覆水中的磷以颗粒磷为主, 这与天然湖泊中磷的主要赋存方式一致 ${ }^{[10]}$.

尽管统计显著性检验发现 $A 、 B 、 C 3$ 个功能水区的氮、磷指标没有显著差异 $(P>0.05)$, 但 $\mathrm{A}$ 区水体 $\mathrm{TN}_{\mathrm{w}}$ 、 $\mathrm{NH}_{4}^{+}-\mathrm{N}_{\mathrm{w}} 、 \mathrm{NO}_{3}^{-}-\mathrm{N}_{w}$ 浓度最高, 均高于开发性水域, B 区浓度次之, C 区浓度最低. $\mathrm{TP}_{w}$ 浓度以 A 和 B 区最高, C 区 最低 (表 1).一般来讲,水体开发往往会导致水体中氮、磷浓度升高, 但 A 区水体中的氮、磷浓度却高于开发 区, 这主要是因为农业面源是水体富营养化的主要污染源 ${ }^{[19]}$, 而 $\mathrm{A}$ 区周围基本是农田,会通过地表径流带 来大量的农业面源污染. 同时 $\mathrm{A}$ 区由于处于非稳沉状态, 随着沉陷面积的扩大, 原农垦地覆水释放也会大大 增加水体中的氮、磷负荷. $\mathrm{B}$ 区作为渔业养殖区,投饵现象以及鱼类的排泄物都会增加水体中的氮、磷浓度, 段登选等对鲁南采煤沉陷区中渔业养殖水域的动态监测也发现, 随着养殖时间的持续, 水体有富营养化风 险 ${ }^{[20]}$. 因此氮、磷污染来源最少的 C 区水体中的氮、磷浓度最低.

不同利用方式沉陷水体的 $\mathrm{pH}_{w}$ 总体呈偏碱性, 在 8 9 正常范围内 (表 1), 无显著差异 $(P>0.05)$. 作为综 合反映水体氧化还原作用的 $\mathrm{Eh}_{\mathrm{w}}$ 指标也无显著性差异 $(P>0.05), 3$ 个功能区水体 $\mathrm{Eh}_{\mathrm{w}}$ 顺序为 $\mathrm{A}$ 区 $>\mathrm{C}$ 区 $>\mathrm{B}$ 区. 各功能水域中的 DO、Chl.a 和 $\mathrm{COD}_{\mathrm{Gr}}$ 浓度均有显著差异 $(P<0.05)$ (表 1). 其中 DO 和 Chl. a 浓度以 B 区最 高, 特别是 Chl.a, 作为反映水体浮游藻类的重要指标, B 区浓度 $\left(3.62 \mathrm{mg} / \mathrm{m}^{3}\right)$ 是 A 区的 4.31 倍, 是 C 区的 24.13 倍, 表明水产养殖会对水体中的浮游藻类繁殖产生较大的促进作用 ${ }^{[21]}$.C 区 $\mathrm{COD}_{\mathrm{Cr}}(69.80 \mathrm{mg} / \mathrm{L})$ 明显 高于 A 区 $(27.95 \mathrm{mg} / \mathrm{L})$ 和 B 区 $(13.27 \mathrm{mg} / \mathrm{L})$, 采样期间发现 C 区的植株都枯萎在水中, 导致水中有机质浓 度很高, $\mathrm{COD}_{\mathrm{Cr}}$ 是其它功能区的 $2 \sim 3$ 倍. 然而 $\mathrm{C}$ 区对应的 $\mathrm{TP}_{w}$ 浓度却未检出, 可能是由于 $\mathrm{C}$ 区的磷以有机态 为主, 通常状况下有机磷主要以颗粒态存在 ${ }^{[22]}$, 磷的这种颗粒特性很容易沉降下来, 再加上 $\mathrm{C}$ 区环境限制基 本无风浪, 水体扰动性小, 使该区上覆水中的磷沉降到水底, $\mathrm{C}$ 区沉积物中 $\mathrm{TP}_{\mathrm{s}}$ 浓度较高就是有力证明.

综上所述, 与 B 区和 C 区相比, A 区具有较高的氮、磷营养盐浓度;3 个功能水区之间以 C 区有机污染 最严重.

\section{2 间隙水中的氮、磷}

尽管统计上没有显著性差异,但后湖沉陷区各功能区间隙水 $\mathrm{TN}_{\mathrm{i}}$ 和 $\mathrm{TP}_{\mathrm{i}}$ 浓度远高于上覆水的 $\mathrm{TN}_{\mathrm{w}}$ 和 $\mathrm{TP}_{\mathrm{w}}$ 浓度 (表 1). 谢伟芳等 ${ }^{[23]}$ 对喀斯特山区溪流水体间隙水和上覆水浓度对比研究发现氮素在上覆水与沉积物 之间存在明显的迁移活动.间隙水作为沉积物与水体的接触带往往反映了上覆水和沉积物之间的物质交换 程度 ${ }^{[24-25]}$. 各个功能区间隙水的氮、磷浓度明显高于上覆水的氮、磷浓度, 说明后湖沉陷区上覆水和沉积物的 氮、磷营养盐交换十分剧烈, 存在较明显的迁移活动.

\section{3 沉积物中的氮、磷}

$\mathrm{NH}_{4}^{+}-\mathrm{N}_{\mathrm{s}}$ 和 $\mathrm{NO}_{3}^{-}-\mathrm{N}_{\mathrm{s}}$ 在 3 个功能区沉积物中的含量均远低于 $\mathrm{TN}_{\mathrm{s}}$ (表 1), 表明沉积物的氮主要是有机 氮 ${ }^{[26]}$. 各个功能区 $\mathrm{NH}_{4}^{+}-\mathrm{N}_{\mathrm{s}}$ 、TP $\mathrm{s}$ 以及 A-P 指标在统计上有显著差异 (表 1), 表明不同水体利用方式会对沉积 物氮、磷的分布有一定影响.上述氮、磷指标上均以 C 区表层沉积物的含量最高 (表 1), 表明水生蔬菜种植会 对水体沉积物的营养盐含量产生重要影响. 这可能与 C 区水体表层覆盖大量有机碎屑有关, 李文朝等和陈芳 等认为水底表层的有机碎屑对沉积物的营养盐含量积累有很大的促进作用 ${ }^{[27-28]}$.B 区沉积物中氮、磷含量高 于 A 区 (表 1) 可能与渔业活动有关, 过量的饵料和鱼的粪便在养殖过程中会沉降在表层沉积物上, 从而增 加沉积物的氮、磷含量.

各功能区表层沉积物氮素含量较高, $\mathrm{TN}_{\mathrm{s}}$ 含量是巢湖周边池塘 $\left(\mathrm{TN}_{\mathrm{s}}: 1.58 \mathrm{~g} / \mathrm{kg} \text {; } \mathrm{TP}_{\mathrm{s}}: 0.93 \mathrm{~g} / \mathrm{kg}\right)^{[18]}$ 的 $2.41 \sim 3.10$ 倍, 是合肥十五里河 $\left(\mathrm{TN}_{\mathrm{s}}: 2.03 \mathrm{~g} / \mathrm{kg} \text {; } \mathrm{TP}_{\mathrm{s}}: 0.88 \mathrm{~g} / \mathrm{kg}\right)^{[29]}$ 的 $1.87 \sim 2.41$ 倍; 各功能区表层沉积物磷 素含量则较低, $\mathrm{TP}_{\mathrm{s}}$ 含量是巢湖周边池塘的 $0.44 \sim 0.59$ 倍, 是十五里河的 $0.47 \sim 0.63$ 倍. 后湖采煤沉陷区沉积 物中氮、磷含量与沉积物的原始矿物成分有很大关系. 该地区底泥基质基本由农剭地构成, 长期的农田旺种 生产往往会施加大量氮肥, 造成土壤氮素较高以至于覆水形成沉积物后氮含量相对较高; 而磷含量相对低 些, 可能受当地施肥方式影响, 一般小麦施肥氮磷比>1, 当地作物主要种植小麦可能是造成沉积物中 $\mathrm{TP}_{\mathrm{s}}$ 含 量相对较低的原因. 
$\mathrm{C} / \mathrm{N}$ 作为沉积物有机质的重要指标, 被许多研究者利用来揭示有机质的来源, 通常认为 $\mathrm{C} / \mathrm{N}$ 大于 20 为 陆源植被 ${ }^{[30]}$. 统计显著性检验发现功能区间的 $\mathrm{C} / \mathrm{N}$ 有明显差异, 其中 A 区 $(26.13)>\mathrm{B}$ 区 $(22.75)>\mathrm{C}$ 区 (17.29), 3 个功能区沉积物有机质的陆源性逐渐降低. 其中 A 区正处于持续沉陷, 导致陆地植被和农作物被 水体淹没, 地表径流携带大量陆源植物残体, 从而造成了本区水体的 $\mathrm{C} / \mathrm{N}$ 值最高. C 区种植莲藕水生蔬菜, 增加了该水体中水生植株的有机质含量, 导致该区 $\mathrm{C} / \mathrm{N}$ 值最低. 各水塘间的 LOI 含量没有显著差异, 以 $\mathrm{A}$ 区 相对最高, C 区次之, B 区最低(表 1). 沉积物烧失量不仅会反映沉积物中的有机质含量, 也会反映碳酸盐的 含量.A 区由于受面源污染影响显著, 地表径流带来大量碳酸盐矿物, 使其 LOI 含量略高于 C 区.

综上所述,各功能区之间, C 区表层沉积物有较高的氮、磷含量和较低的 C/N.

表 1 后湖不同功能区理化性质统计分析结果

Tab.1 Statistical analysis results of physico-chemical properties of different water areas in Lake Houhu

\begin{tabular}{|c|c|c|c|c|c|c|}
\hline 检测物 & 指标 & A 区 & B 区 & C 区 & $F$ & $P$ \\
\hline \multirow[t]{10}{*}{ 上覆水 } & $\mathrm{DO} /(\mathrm{mg} / \mathrm{L})$ & $5.08 \pm 0.14$ & $5.69 \pm 0.17$ & $5.62 \pm 0.12$ & 4.861 & 0.037 \\
\hline & $\mathrm{pH}_{\mathrm{w}}$ & $8.28 \pm 0.03$ & $8.36 \pm 0.09$ & $8.17 \pm 0.00$ & 1.707 & 0.235 \\
\hline & $\mathrm{Eh}_{\mathrm{w}} / \mathrm{mV}$ & $134.33 \pm 2.86$ & $124.50 \pm 3.43$ & $128.50 \pm 2.50$ & 1.242 & 0.334 \\
\hline & $\mathrm{TN}_{\mathrm{w}} /(\mathrm{mg} / \mathrm{L})$ & $6.60 \pm 0.50$ & $5.82 \pm 0.36$ & $5.80 \pm 0.87$ & 0.771 & 0.491 \\
\hline & $\mathrm{NH}_{4}^{+}-\mathrm{N}_{\mathrm{w}} /(\mathrm{mg} / \mathrm{L})$ & $0.70 \pm 0.32$ & $0.34 \pm 0.05$ & $0.30 \pm 0.04$ & 0.598 & 0.570 \\
\hline & $\mathrm{NO}_{3}^{-}-\mathrm{N}_{\mathrm{w}} /(\mathrm{mg} / \mathrm{L})$ & $0.24 \pm 0.01$ & $0.20 \pm 0.02$ & $0.16 \pm 0.01$ & 0.397 & 0.684 \\
\hline & $\mathrm{TP}_{\mathrm{w}} /(\mathrm{mg} / \mathrm{L})$ & $0.02 \pm 0.01$ & $0.02 \pm 0.02$ & - & 0.570 & 0.585 \\
\hline & $\mathrm{TDP}_{\mathrm{w}} /(\mathrm{mg} / \mathrm{L})$ & - & - & - & - & - \\
\hline & Chl.a/ $\left(\mathrm{mg} / \mathrm{m}^{3}\right)$ & $0.84 \pm 0.10$ & $3.62 \pm 1.14$ & $0.15 \pm 0.01$ & 6.828 & 0.016 \\
\hline & $\mathrm{COD}_{\mathrm{Cr}} /(\mathrm{mg} / \mathrm{L})$ & $27.95 \pm 4.03$ & $13.27 \pm 5.19$ & $69.80 \pm 0.48$ & 23.901 & 0.000 \\
\hline \multirow[t]{2}{*}{ 间隙水 } & $\mathrm{TN}_{\mathrm{i}} /(\mathrm{mg} / \mathrm{L})$ & $18.07 \pm 4.17$ & $23.20 \pm 7.45$ & $19.84 \pm 2.46$ & 1.197 & 0.346 \\
\hline & $\mathrm{TP}_{\mathrm{i}} /(\mathrm{mg} / \mathrm{L})$ & $0.09 \pm 0.03$ & $0.06 \pm 0.03$ & $0.07 \pm 0.07$ & 2.241 & 0.162 \\
\hline \multirow[t]{7}{*}{ 沉积物 } & $\mathrm{TN}_{\mathrm{s}} /(\mathrm{g} / \mathrm{kg})$ & $4.12 \pm 0.48$ & $3.80 \pm 0.70$ & $4.90 \pm 0.00$ & 2.796 & 0.114 \\
\hline & $\mathrm{NH}_{4}^{+}-\mathrm{N}_{\mathrm{s}} /(\mathrm{g} / \mathrm{kg})$ & $0.01 \pm 0.01$ & $0.03 \pm 0.01$ & $0.09 \pm 0.01$ & 39.541 & 0.000 \\
\hline & $\mathrm{NO}_{3}^{-}-\mathrm{N}_{\mathrm{s}} /(\mathrm{g} / \mathrm{kg})$ & $0.01 \pm 0.00$ & $0.01 \pm 0.00$ & $0.01 \pm 0.00$ & 0.423 & 0.667 \\
\hline & $\mathrm{TP}_{\mathrm{s}} /(\mathrm{g} / \mathrm{kg})$ & $0.41 \pm 0.05$ & $0.43 \pm 0.03$ & $0.55 \pm 0.07$ & 6.695 & 0.017 \\
\hline & $\mathrm{A}-\mathrm{P} /(\mathrm{g} / \mathrm{kg})$ & $0.02 \pm 0.00$ & $0.02 \pm 0.00$ & $0.04 \pm 0.00$ & 44.541 & 0.000 \\
\hline & $\mathrm{C} / \mathrm{N}$ & $26.13 \pm 3.87$ & $22.75 \pm 2.50$ & $17.29 \pm 0.35$ & 5.800 & 0.024 \\
\hline & $\mathrm{LOI} / \%$ & $7.55 \pm 0.01$ & $5.71 \pm 0.01$ & $6.13 \pm 0.00$ & 3.135 & 0.093 \\
\hline
\end{tabular}

“一”表示未检出.

\section{3 讨论}

\section{1 氮、磷在沉积物-水界面之间的迁移关系}

在湖泊体系中, 沉积物一水体界面间营养盐的交换主要通过间隙水来实现. 张水元等对保安湖水体中氮、 磷进行研究发现当间隙水中的氮、磷浓度超过上覆水时, 沉积物所溶解的氮、磷营养盐就会释放到上覆水 中 ${ }^{[31]}$. 采样期间, 水体分层消失, 上、下水层混合均匀, 上覆水采集的表层水能很好地反映整个水体的水质状 况. 本研究中 A、B、C 3 个功能区间隙水的总氮和总磷平均浓度均高于上覆水的, 更高于溶解态的氮、磷浓度. 由于间隙水与上覆水中营养盐存在明显的浓度差, 间隙水中的营养盐必然会通过分子扩散形式迁移到上覆 水中. 因此, 后湖采煤沉陷水体的沉积物经间隙水向上覆水释放氮、磷营养盐. 在研究期间, 沉积物对水体中 的氮、磷主要起着源的作用.

为了比较各个功能区氮、磷的迁移, 利用迁移速率即 (间隙水-上覆水)/间隙水来进行分析, 由于上覆水 中 $\mathrm{TDP}_{\mathrm{w}}$ 未检出, 所以对间隙水和上覆水的总氮、总磷进行计算比较, 从侧面反映各个功能区的氮、磷迁移差 异. 结果表明, 总氮的迁移速率以 B 区和 C 区较高, A 区最低. 然而总磷的迁移速率却以 C 区明显高于其它两 区, B 区最低( 图 2). C 区较高的磷迁移速率与上覆水磷的沉降和该区沉积物中高含量的磷密切相关. B 区 
氮、磷迁移速率之间出现了较大的反差, $\mathrm{A}$ 区和 $\mathrm{B}$ 区上覆水中 $\mathrm{TP}_{\mathrm{w}}$ 具有相同的浓度, 但 $\mathrm{B}$ 区间隙水的 $\mathrm{TP}_{\mathrm{i}}$ 浓 度却是 A 区的 0.67 倍(表 1),B 区磷的迁移速率明显受间隙水含量的影响. 通常认为间隙水的营养盐含量 受生产和消耗之间平衡的影响, 前者受有机质含量、沉积物的释放等影响, 后者与底栖生物、水动力条件以 及矿化作用等有很大关系 ${ }^{[32]}$.A 区和 B 区沉积物中 $\mathrm{TP}_{\mathrm{s}}$ 及 A-P 含量相差不大, 但 $\mathrm{LOI}$ 含量以 A 区较高, 因此 间隙水中磷的含量差异可能与有机质含量密切相关.
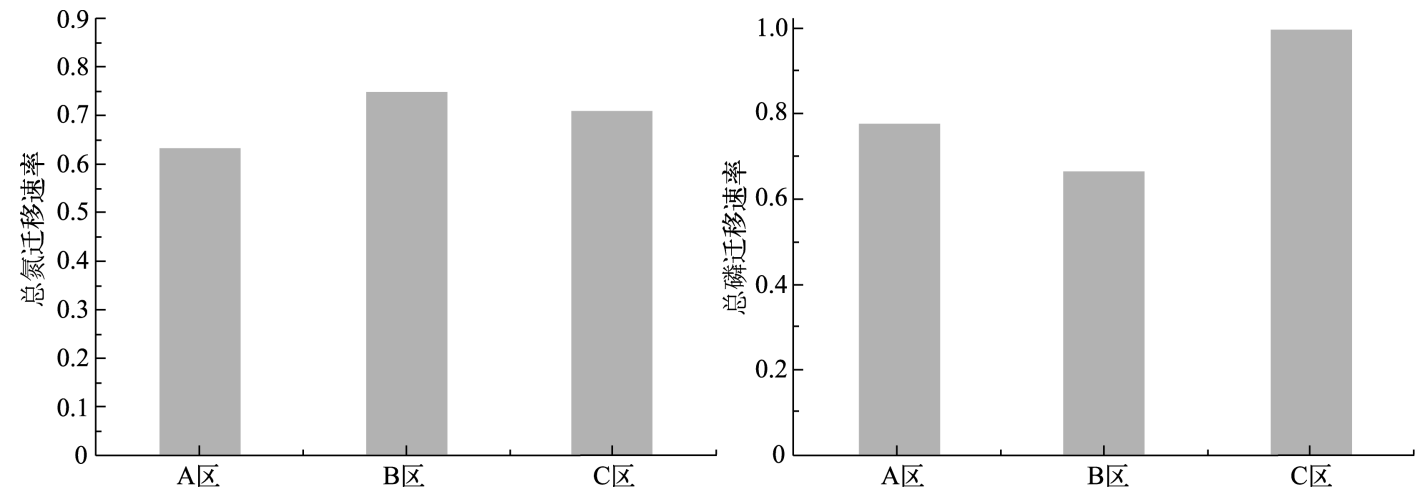

图 2 后湖不同功能区总氮和总磷的迁移速率

Fig. 2 Distribution of total nitrogen and total phosphorus of different water areas in Lake Houhu

\section{2 氮磷比在上覆水、间隙水和沉积物的变化}

所调查的研究区上覆水的 $\mathrm{TN}_{\mathrm{w}}$ 浓度为 4.83 8.47 mg/L, $\mathrm{TP}_{w}$ 浓度为 $0.02 \sim 0.08 \mathrm{mg} / \mathrm{L}$. 张冰等对张集和顾桥 沉陷区的研究表明 ${ }^{[33]}$, 该沉陷区水体中 TN 浓度为 $0.02 \sim 2.32 \mathrm{mg} / \mathrm{L}$, TP 浓度为 $0.201 \sim 0.328 \mathrm{mg} / \mathrm{L}$. 与前人研究 结果相比, 后湖沉陷区各功能区上覆水的 $\mathrm{TN}_{\mathrm{w}}$ 浓度较高, $\mathrm{TP}_{\mathrm{w}}$ 浓度较低. 从国内湖泊富营养化评级标准来 看 ${ }^{[34]}$, A 、 B 和 C 3 个功能区的总氮浓度已经处于重度富营养化水平, 总磷浓度的富营养化水平较低, 一般认 为氮磷质量比 $>10$ 时, 磷为藻类的限制因素 ${ }^{[35]}$, 反之氮成为限制因子.

通过对 3 个功能区氮磷比的分析 (表 2) 可以看出,各区上覆水中的氮 磷比远高于武汉东湖典型磷限制富营 养状态浅水湖泊,该湖泊沉积物对营 养盐扮演着源的角色 ${ }^{[37]}$.C 区由于磷 沉降的原因,上覆水显然为磷限制, 氮 磷比最高, A 区比值次之, B 区最低.各 功能区间隙水氮磷比为 $\mathrm{B}$ 区 $>\mathrm{C}$ 区 $>\mathrm{A}$ 表 2 后湖不同功能区上覆水、间隙水与沉积物的氮磷比

Tab. $2 \mathrm{~N} / \mathrm{P}$ ratios of overlying water, interstitial water and sediment of different water areas in Lake Houhu

\begin{tabular}{crrcc}
\hline 位置 & A 区 & B 区 & C 区 & 武汉东湖[36] \\
\hline 上覆水 & 330.00 & 291.00 & - & $15.7 \sim 40.6$ \\
间隙水 & 200.78 & 386.67 & 283.43 & - \\
沉积物 & 10.05 & 8.84 & 8.91 & $2.94 \sim 3.04$ \\
\hline
\end{tabular}
区, 数值也远高于标准限定值, 可以看 出间隙水中的营养盐也为磷限制.沉积物是水体中氮、磷“汇” 和 “源”的容纳场. 在研究期间, 后湖沉积物主 要起着源的作用. 根据对比发现, 各功能区沉积物的氮磷比是武汉东湖的 2.91 3.42 倍, 可以推断后湖采煤 沉陷区沉积物基质对水体氮、磷限制起着重要作用, 因此原覆水土壤中氮、磷含量矿物分布可能是影响淮南 采煤沉陷区水体主要磷控制 ${ }^{[12]}$ 的关键因素.

从沉积物到间隙水的氮磷比变化来看, 氮磷比在 3 个功能区均增加 (表 2), 这与水动力条件和沉积物对 氮、磷释放解析强度等诸多因素有很大关系. 在该研究中由于氮、磷在沉积物水体界面的迁移是从间隙水向 上覆水移动, 各功能区间隙水和上覆水中氮磷比的变化趋势也一定程度上反映了上覆水的氮、磷消耗和来 源影响. A 区从间隙水到上覆水氮磷比变大, B 区变小 (表 2), 这除了与浓度扩散、生物扰动、营养盐水平迁 移等因素有关外, 还可能与 $\mathrm{A}$ 区面源的影响和沉陷扩大造成的水土流失有很大关系, 土壤中较高含量的氮 对 A 区上覆水中氮磷比的升高有重要影响. B 区降低的氮磷比可能与该水体中较为丰富的藻类对磷的消耗 
有一定关系.

综上所述, 后湖采煤沉陷区虽然开发规划时间仅仅几年, 然而水体中却表现出高浓度的氮污染现象, 水 体中较高的氮磷比使磷成为该水域最重要的控制元素. 同时, 由于沉积物处于释放阶段, 未来水体富营养化 风险可能更大. 因此, 今后我们需要对采煤沉陷水体的开发和重建予以重视, 有针对性地减少外源污染物输 人、预防水体富营养化、合理调控水体氮磷比例结构等, 在保证沉陷区水体生态系统健康稳定的前提下合理 开发.

\section{4 结论}

1) 后湖采煤沉陷区水体中含有较高的氮营养盐含量, 然而均表现出磷缺失的状态. 由于水体利用方式 和环境特征的不同, 各功能区氮、磷在上覆水和沉积物中表现出明显差异. 其中, 上覆水中以未开发区氮、磷 浓度最高, 沉积物中以水生蔬菜区氮、磷含量最高.

2) 从氮、磷在沉积物一水体界面的迁移变化来看, 后湖沉陷区沉积物还处于释放营养盐状态, 其中在水 产养殖区氮、磷迁移变化反差较大. 然而由于面源污染以及煤炭的持续开采等人类活动的影响, 外源输人对 沉陷区水体富营养化也起着重要作用.

\section{5 参考文献}

[ 1 ] 范英宏, 陆兆华, 程建龙等. 中国煤矿区主要生态环境问题及生态重建技术. 生态学报, 2003, 23(10): 2144-2152.

[ 2 ] 李新举, 胡振琪, 李 晶等. 采煤塌陷地复旺土壤质量研究进展. 农业工程学报, 2007, 23(6): 276-280.

[ 3 ] 孙鹏飞, 易齐涛, 许光泉. 两淮采煤沉陷积水区水体水化学特征及影响因素. 煤炭学报, 2014, 39(7): 1345-1353.

[4] 高 波, 冯启言, 孟庆俊. 采煤塌陷地积水对土壤氮素矿化过程的影响. 环境污染与防治, 2013, 35(8): 1-8.

[ 5] 刘响响, 程 桦, 郑刘根等. 淮南采煤沉陷水体中氮磷的分布特征及环境意义. 中国科学技术大学学报, 2014, 44 (11) : 926-932.

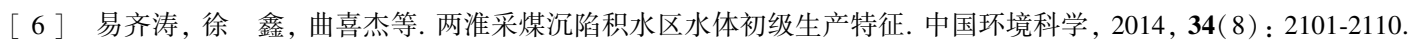

[ 7 ] Yang LB, Lei K, Meng W et al. Temporal and spatial changes in nutrients and chlorophyll-a in a shallow lake, Lake Chaohu, China: An 11-year investigation. Journal of Environmental Sciences, 2013, 25(6) : 1117-1123.

[ 8 ] Huang CC, Wang XL, Yang H et al. Satellite data regarding the eutrophication response to human activities in the plateau lake Dianchi in China from 1974 to 2009. Science of the Total Environment, 2014, 485/486: 1-11.

[ 9 ] 许 海, 朱广伟, 秦伯强等. 氮磷比对水华蓝藻优势形成的影响. 中国环境科学, 2011, 31(10): 1676-1683.

[10］秦伯强, 杨柳燕, 陈非洲等. 湖泊富营养化发生机制与控制技术及其应用. 科学通报, 2006, 51(16)：1857-1866.

[11] 曲喜杰, 易齐涛, 胡友彪等. 两淮采煤沉陷积水区水体营养盐时空分布及富营养化进程. 应用生态学报, 2013, 24 (11) : 3249-3258.

[12] 王婷婷, 易齐涛, 胡友彪等. 两淮采煤沉陷区水域水体富营养化及氮磷限制模拟实验. 湖泊科学, 2013, 25(6): 916-926. DOI 10. 18307/2013. 0616.

[13] 谢 凯, 张雁秋, 易齐涛等. 淮南潘一矿塌陷水域沉积物中磷的赋存和迁移转化特征. 中国环境科学, 2012, 32 (10) : 1867-1874.

[14] 陈晓晴, 高良敏, 卓利玲. 谢桥采煤塌陷水域氮、磷时空分布特征. 环境化学, 2013, 32(3)：446-450.

[15] 计承富, 桂和荣. 矿区塌陷塘水体主要营养盐的调查分析. 哈尔滨工业大学学报, 2009, 21(2) : 202-204.

[16] 谢 凯, 易齐涛, 孙鹏飞. 采煤沉陷积水区土壤覆水初期氧化还原反应过程与磷迁移转化的耦合研究. 环境科学 学报, 2013, 33(11): 3101-3110.

[17] 易齐涛, 孙鹏飞, 谢 凯等. 区域水化学条件对淮南采煤沉陷区水域沉积物磷的吸附特征的影响研究. 环境科学, 2013, 34 (10) : 3894-3903.

[18] 孙庆业, 马秀玲, 阳贵德等. 巢湖周围池塘氮、磷和有机质研究. 环境科学, 2010, 31(7) : 1510-1515.

[19] Sims JT, Goggin N, McDermott J. Nutrient management for water quality protection: integraing research into environmental policy. Water Science and Technology, 1999, 39(12) : 291-298.

[20] 段登选, 许国晶, 栗 明等. 鲁南采煤塌陷水域渔业生态环境状况研究. 中国农学通报, 2015, 31(5) : 75-80. 
[21] 胡家文, 姚维志. 养殖水体富营养化及其防治. 水利渔业, 2005, 25(6) : 74-76.

[22] Wetzel RG. Limnology, lake and river ecosystems. London: Academy Press, 2001: 245-260.

[23] 谢伟芳, 夏品华, 林 陶等. 喀斯特山区溪流上覆水-孔隙水-沉积物中不同形态氮的赋存特征及其迁移一以麦 西河为例. 中国岩溶, 2011, 30(1): 9-15.

[24] 陈永川, 汤 利. 沉积物一水体界面氮磷的迁移转化规律研究进展. 云南农业大学学报, 2005, 20(4): 527-533.

[25] 高 丽, 杨 浩, 周健民等. 滇池沉积物磷的释放以及不同形态磷的贡献. 农业环境科学学报, 2004, 23(4): 731-734.

[26] 李如忠, 李 峰, 周爱佳等. 巢湖十五里河沉积物氮磷形态分布及生物有效性. 环境科学, 2012, 33 (5): 1503-1510.

[27] 李文朝, 尹澄清, 陈开宁. 关于湖泊沉积物磷释放及测定方法的雏议. 湖泊科学, 1999, 11(4) : 296-303. DOI 10. 18307/1999. 0402.

[28] 陈 芳, 夏卓英, 宋春雷等. 湖北省若干浅水湖泊沉积物有机质与富营养化的关系. 水生生物学报, 2007, 31 (4) : 467-472.

[29] 李如忠, 李 峰. 巢湖十五里河沉积物生物有效性氮磷分布及相关性. 环境科学研究, 2011, 24(8): 874-881.

[30] 徐 康, 刘付程, 安宗胜等. 巢湖表层沉积物中磷赋存形态的时空变化. 环境科学, 2011, 32(11): 3254-3263.

[31] 张水元, 刘瑞秋, 黎道丰. 保安湖沉积物和间隙水中氮和磷的含量及其分布. 水生生物学, 2000, 24 (5): 434-438.

[32] 何 桐, 谢 健, 余汉生等. 大亚湾表层沉积物间隙水与上覆水中营养盐分布特征. 环境科学学报, 2008,28 (11) : 2361-2368.

[33] 张 冰, 严家平, 范廷玉等. 采煤塌陷水域富营养化评价与分析. 煤炭技术, 2012, 31(1): 159-161.

[34] 王明翠, 刘雪芹, 张建辉. 湖泊富营养化评价方法及分级标准. 中国环境监测, 2002, 18( 5) : 47-49.

[35] 许 海, 朱广伟, 秦伯强等. 氮磷比对水华蓝藻优势形成的影响. 中国环境科学, 2011, 31(10): 1676-1683.

[36] 冯 峰, 方 涛, 刘剑形. 武汉东湖沉积物氮磷形态垂向分布研究. 环境科学, 2006, 27(6) : 1078-1082.

[37] 张水元, 刘囸霞, 华 俐. 武汉东湖沉积物和沉积物间隙水中氮和磷的含量及其分布. 水生生物学报, $1987, \mathbf{1 1}$ (2) : 131-138. 